\title{
Quercetin enhances TRAIL-induced apoptosis in prostate cancer cells via increased protein stability of death receptor 5
}

\author{
Young-Hwa Jung a , Jeonghoon Heo ${ }^{a}$, Yong J. Lee ${ }^{\text {b }}$, Taeg Kyu Kwon ${ }^{c}$, Young-Ho Kim ${ }^{\text {a,* }}$ \\ a Department of Molecular Biology and Immunology, College of Medicine, Kosin University, Busan 602-703, Korea \\ b Department of Surgery, School of Medicine, University of Pittsburgh, Pittsburgh, PA 15213, USA \\ c Department of Immunology, School of Medicine, Keimyung University, Taegu 700-712, Korea
}

\section{A R T I C L E I N F O}

\section{Article history:}

Received 25 November 2009

Accepted 10 January 2010

\section{Keywords:}

Quercetin

Death receptor 5

Tumor necrosis factor-related

apoptosis-inducing ligand (TRAIL)

Apoptosis

\begin{abstract}
A B S T R A C T
Aims: Quercetin has been shown to enhance tumor necrosis factor-related apoptosis-inducing ligand (TRAIL)-induced apoptosis of prostate cancer cells via mechanisms that include upregulation of death receptor (DR) 5, a protein reported to play an important role in sensitizing cancer cells to apoptosis. We aimed to determine the specific mechanisms underlying quercetin-induced DR5 expression.

Main methods: Human prostate cancer cells were exposed to quercetin and TRAIL. Trypan blue assays and terminal transferase dUTP nick-end labeling (TUNEL) assays evaluated changes in TRAIL resistance after quercetin treatment, and flow cytometry examined quercetin-induced death receptor expression in DU-145 cells. Western blotting, reverse transcription-polymerase chain reaction (RT-PCR) and transiently transfection were utilized to confirm apoptotic patterns of prostate cancer cells.

Key findings: After stimulation with quercetin, DU-145 cells exhibited stronger sensitization to TRAIL. Quercetin treatment enhanced TRAIL-induced activation proteins in the caspase pathway, such as poly (ADPribose) polymerase (PARP), caspase-3, and caspase-9. Quercetin dose-dependently increased DR5 levels in prostate cancer cells, which was mediated by increased transcription and protein stability, but not mRNA stability. Ectopic expression of DR5 dose-dependently increased TRAIL-induced apoptosis.

Significance: Our results showed that the role of quercetin and TRAIL combination therapy may provide a novel strategy for treating prostate cancer by overcoming critical mechanisms of apoptosis resistance.
\end{abstract}

(c) 2010 Elsevier Inc. All rights reserved.

\section{Introduction}

Tumor necrosis factor (TNF)-related apoptosis-inducing ligand (TRAIL), a member of the TNF family, induces apoptosis selectively in cancer cells in vitro and in vivo, while exerting only negligible effects on normal cells (Ashkenazi et al. 1999; Keane et al. 1999; Lawrence et al. 2001; Pitti et al. 1996; Walczak et al. 1999). The potential usefulness of TRAIL as an anticancer agent has been supported by studies in animal models showing selective toxicity to human tumor xenografts (Ashkenazi et al. 1999; Walczak et al. 1999). However, many tumors are still resistant to TRAIL.

Death receptor 5 (DR5; TRAIL-R2) and death receptor 4 (DR4; TRAIL-R1) are members of the TNF family that are activated by TRAIL (Pan et al. 1997; Sheridan et al. 1997; Walczak et al. 1997). TRAIL induces formation of death-inducing signal complexes (Sprick et al. 2000; Kischkel et al. 2000). However, recent reports have shown that some cancer cells are resistant to the apoptotic effects of TRAIL (Ozören et al. 2000; Wang and El-Deiry 2003; Ivanov et al. 2003).

\footnotetext{
* Corresponding author. Tel.: + 8251990 6505; fax: +82 519903081. E-mail address: kimyh@kosin.ac.kr (Y.-H. Kim).
}

TRAIL-resistant cells can be sensitized by chemotherapeutic drugs in vitro, indicating that combined therapy may be useful to treat TRAILresistant cancer cells. Several reports have shown that the DR5 plays an important role in sensitizing cancer cells to apoptosis induced by TRAIL and chemotherapeutic agents (Kim et al. 2008a,b,c; Jung et al. 2006).

Quercetin is a ubiquitous bioactive plant flavonoid that has been shown to inhibit cell proliferation in several cancer types. We previously reported that quercetin decreased phosphorylation of Akt and expression of survivin in prostate cancer cells (Kim and Lee 2007; Kim et al. 2008d). Studies investigating molecular mechanisms that underlie the inhibition of cell proliferation by quercetin demonstrated that a treatment including quercetin triggered numerous cellular events including DR5 upregulation (Kim et al. 2008b; Psahoulia et al. 2007), p53 activation (Kuo et al. 2004; Tanigawa et al. 2008), cell cycle arrest (Lee et al. 2006), and induction of caspasemediated apoptosis in some cancer cells. However, the specific molecular mechanisms underlying the upregulation of DR5 by quercetin remain unclear. The aim of the present study was to characterize the regulation of DR5 by quercetin in prostate cancer cells. We found that quercetin increases the stability of the DR5 protein, which results in synergistic enhancement of TRAIL-induced 
apoptosis in human prostate cancer cells. Our results support the possibility that a combined treatment of quercetin with TRAIL will be a promising new cancer therapeutic.

\section{Materials and methods}

Reagents

Recombinant human TRAIL ligand was purchased from KOMA Biotech, Inc. (Seoul, Korea). Quercetin, cycloheximide (CHX), and actinomycin D were obtained from Sigma Chemical Co. (St Louis, MO). The caspase inhibitor Z-VAD-FMK was purchased from Calbiochem (San Diego, CA); a stock solution was prepared in dimethyl sulfoxide (DMSO). Polyclonal anti-poly (ADP-ribose) polymerase (PARP), anti-DR5, anti-DR4, anti-decoy receptor (DcR) 2, and anti-actin antibodies were purchased from Santa Cruz (Santa Cruz, CA); anti-caspase-3 and anti-caspase-9 antibodies were purchased from Cell Signaling (San Diego, CA). Monoclonal anti-caspase-8 was purchased from Upstate Biotechnology (Santa Cruz, CA).

\section{Cell culture and survival assay}

Human prostate adenocarcinoma DU-145, PC-3, and LNCaP cell lines were obtained from the American Type Culture Collection (ATCC; Rockville, MD). Cells were cultured in Dulbecco's modified eagles medium (DMEM) (Gibco BRL, Gaithersburg, MD) containing 10\% fetal
A

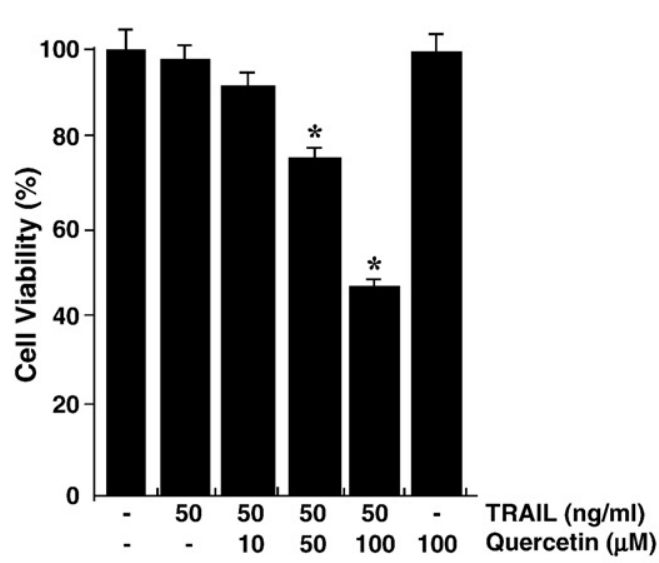

C

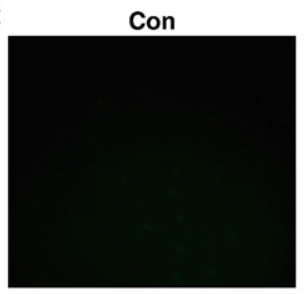

TRAIL

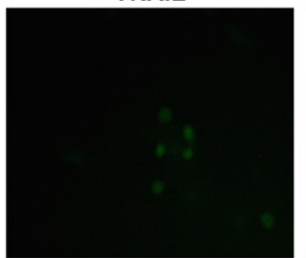

Quercetin

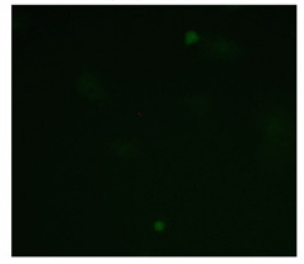

Quercetin+TRAIL

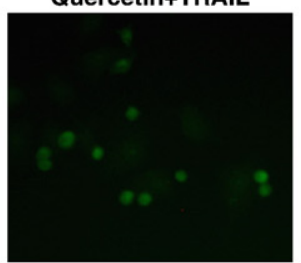

D

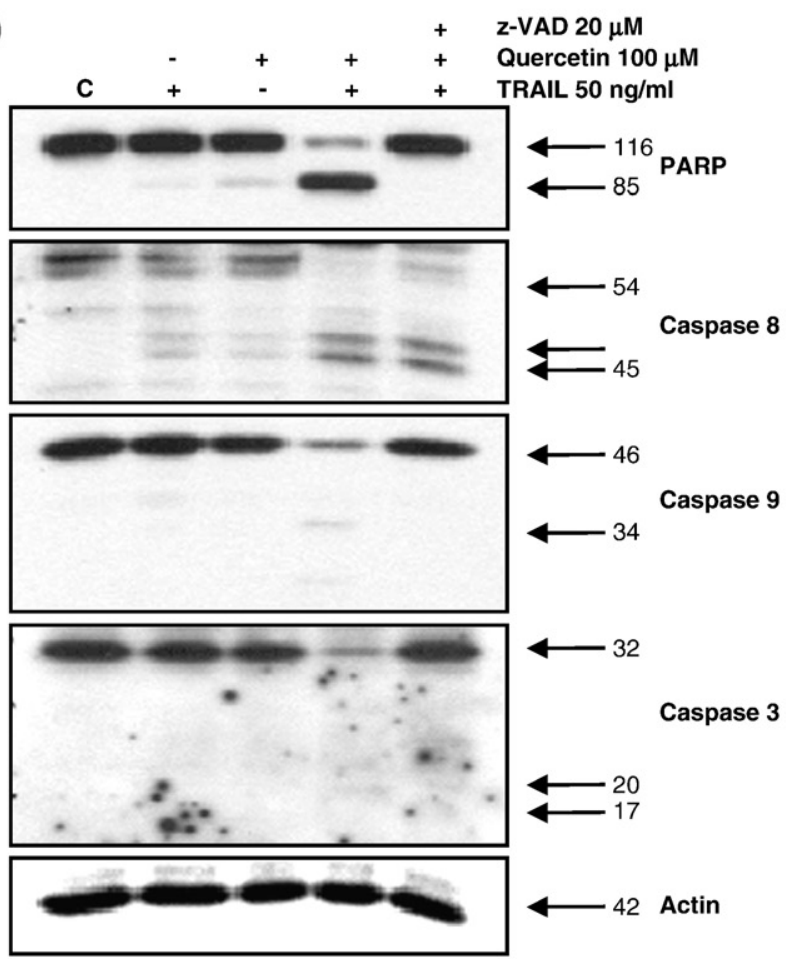

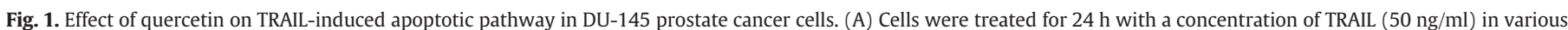

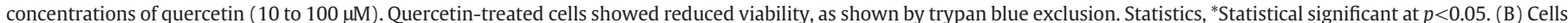

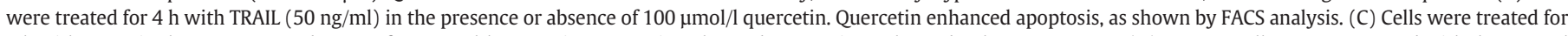

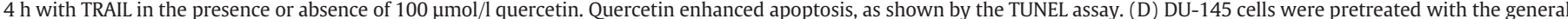

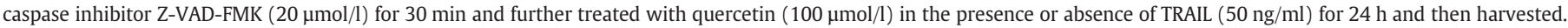

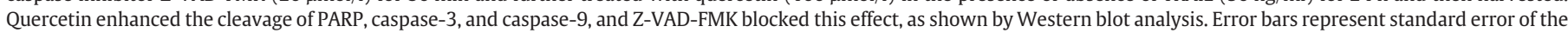
mean (SEM) for three separate experiments. Con, control. 
bovine serum (HyClone, Logan, UT). For trypan blue exclusion assay, trypsinized cells were pelleted and resuspended in $0.2 \mathrm{ml}$ of medium, $0.5 \mathrm{ml}$ of $0.4 \%$ trypan blue solution, and $0.3 \mathrm{ml}$ of phosphate-buffered saline solution (PBS). The samples were mixed thoroughly, incubated at room temperature for $15 \mathrm{~min}$, and visualized by light microscopy. At least 300 cells were counted for each survival determination.

\section{TUNEL assay}

For detection of apoptosis by the terminal deoxynucleotidyl transferase dUTP nick end labeling (TUNEL) method, cells were plated in slide chambers. After treatment, cells were fixed with $70 \%$ ethanol in PBS. The $50-\mu l$ TUNEL reaction was carried out at $37{ }^{\circ} \mathrm{C}$ for $1 \mathrm{~h}$ with $0.3 \mathrm{nmol}$ of fluorescein isothiocyante-12-dUTP, $3 \mathrm{nmol}$ of dATP, $2 \mu \mathrm{l}$ of $\mathrm{CoCl}_{2}$, $25 \mathrm{U}$ of terminal deoxynucleotidyl transferase, and TdT buffer. The reaction was terminated with $2 \mu \mathrm{l}$ of $0.5 \mathrm{M}$ ethylenediaminetetraacetic acid (EDTA). Cells were visualized by fluorescence microscopy.

A
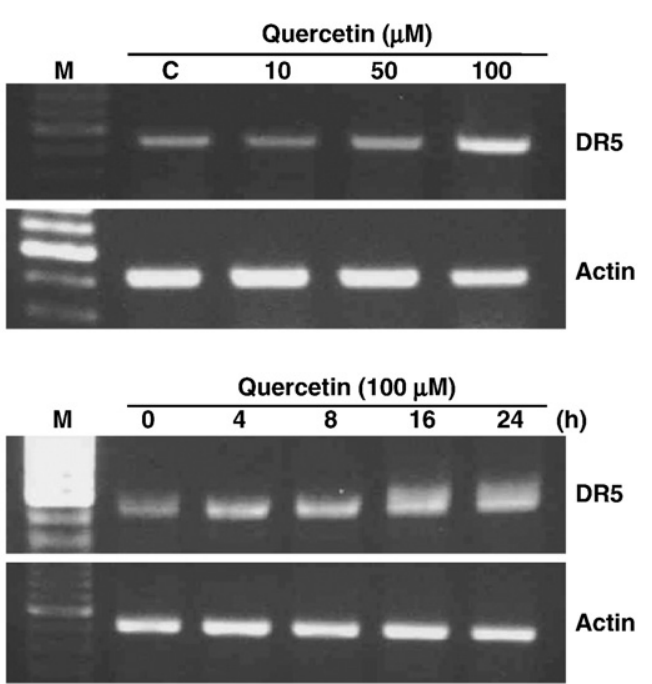

B

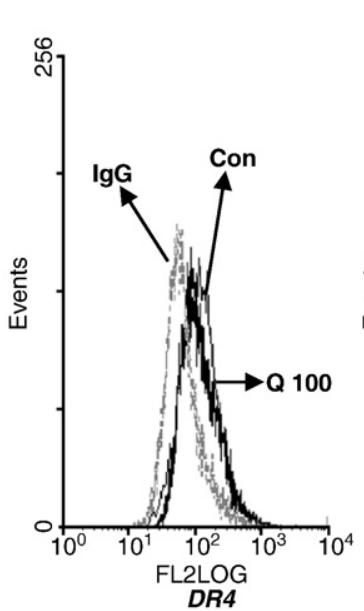

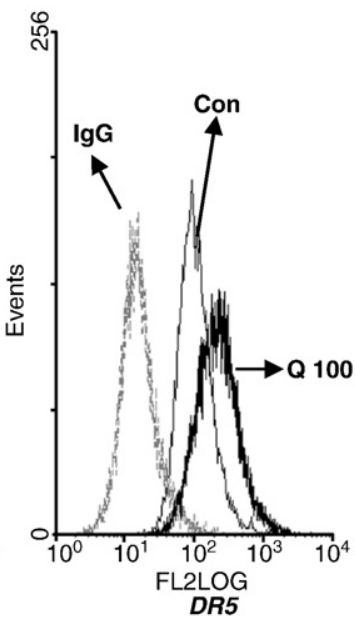

Semi-quantitative reverse transcription-polymerase chain reaction analysis

Total RNA was extracted from DU-145 cells using the TRIzol reagent (Invitrogen, Carlsbad, CA). Complementary DNA was synthesized from $2 \mu \mathrm{g}$ of total RNA using MMLV reverse transcriptase (TaKaRa Co., Ltd. Japan). Human DR5 mRNA was amplified using the sense primer 5'-AAG ACC CTT GTG CTC GTT GT-3' and the antisense primer 5'-GAC ACA TTC GAT GTC ACT CCA-3'. The polymerase chain reaction (PCR) was carried out as follows: 35 cycles of $94^{\circ} \mathrm{C}$ for $30 \mathrm{~s}$, $60{ }^{\circ} \mathrm{C}$ for $45 \mathrm{~s}$, and $72{ }^{\circ} \mathrm{C}$ for $30 \mathrm{~s}$, followed by a 5 -min extension stage at $72{ }^{\circ} \mathrm{C}$. Amplification products were analyzed electrophoretically on $1.0 \%$ agarose gel containing $0.1 \mu \mathrm{g} / \mathrm{ml}$ ethidium bromide.

\section{Plasmids, transfection, and luciferase assay}

The luciferase DR5 plasmid (pLUC-DR5 [-605]) was a gift from Dr. T. Sakai (Kyoto Prefectural University) and the myc-DR5 expression
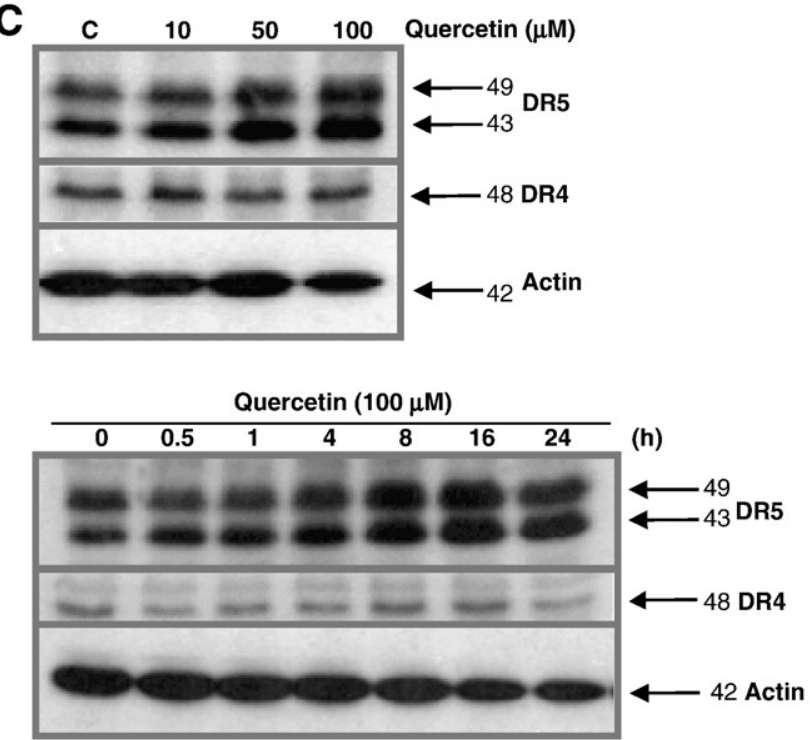

D
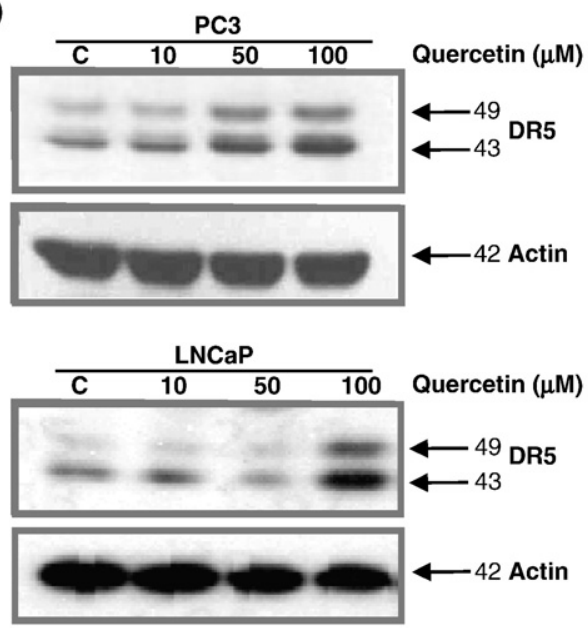

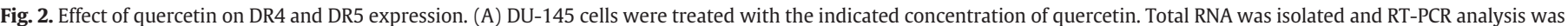

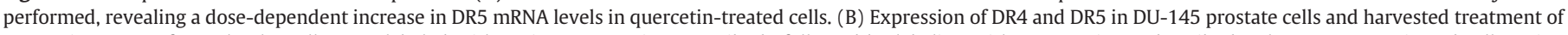

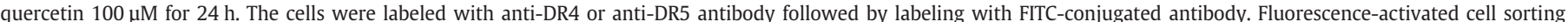

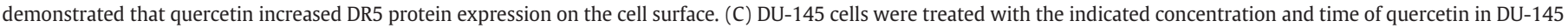

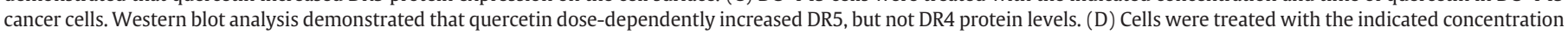
of quercetin in PC3 and LNCaP cancer cells. Actin was shown as an internal standard. Con, control; Q quercetin. 
plasmid (myc-DR5) was kindly provided by Dr. Y. Lee (University of Pittsburgh). Cell were seeded in 6 -well plates at $2.5 \times 10^{5}$ cells/plate and grown for $24 \mathrm{~h}$ before transfection. Cells were co-transfected with $1 \mathrm{~g}$ of various plasmid constructs and $1 \mathrm{~g}$ of the pCMV galactosidase normalization plasmid by $4 \mathrm{~h}$ incubation with Lipofectamine reagent (Invitrogen, Carlsbad, CA). Luciferase and galactosidase activities were determined according to the manufacturer's protocol (Promega, Madison, WI).

\section{Fluorescence-activated cell sorting for DR5 and Annexin V analysis}

Expression of DR4 and DR5 was evaluated by flow cytometry before and after treatment with quercetin $(100 \mu \mathrm{M})$. DU-145 cells were seeded $24 \mathrm{~h}$ before treatment in 6-well plates. After 24-h treatment, the attached cells were collected, washed twice with PBS, and incubated at $4{ }^{\circ} \mathrm{C}$ with antibodies against DR4 and DR5, then incubated with a secondary fluorescein isothiocyanate (FITC)-conjugated IgG, and finally analyzed by flow cytometry. To determine apoptosis, DU-145 cells were stimulated with quercetin and/or TRAIL, and apoptotic cell death was measured by flow cytometry using FITC-conjugated Annexin V and propidium iodide (PI) (PharMingen, San Diego, CA) according to the manufacturer's instructions.

\section{Immunoblot analysis}

Cell lysates containing equal amounts of protein $(20 \mu \mathrm{g})$ were separated by SDS-PAGE and electrophoretically transferred to nitrocellulose membrane. The nitrocellulose membrane was blocked overnight with $5 \%$ nonfat dry milk in PBS-Tween-20 (0.1\%, v/w) at $4{ }^{\circ} \mathrm{C}$. The membrane was incubated with primary antibody (diluted according to the manufacturer's instructions) for $2 \mathrm{~h}$. Horseradish peroxidase-conjugated anti-rabbit or anti-mouse IgG was used as the secondary antibody. Immunoreactive protein was visualized by chemiluminescence (ECL, Amersham, Arlington Heights, IL) Western blotting according to the manufacturer's instructions.

\section{Statistical analysis}

Three or more separate experiments were performed. Statistical analysis was done by Student's $t$-test or ANOVA. A $P$ value $<0.05$ was considered to have a pronounced difference between experimental and control groups.

\section{Results}

Quercetin enhances TRAIL-induced apoptosis through caspase pathway

To investigate the effect of quercetin on TRAIL-induced apoptosis, human prostate DU-145 cells were treated with various concentrations of TRAIL in the presence or absence of quercetin. Treatment of DU-145 cells with $50 \mathrm{ng} / \mathrm{ml}$ TRAIL in the presence of $50 \mu \mathrm{mol} / \mathrm{l}$ and $100 \mu \mathrm{mol} / \mathrm{l}$ quercetin decreased cell viability to $60 \%$ and $10 \%$ over $24 \mathrm{~h}$, respectively (Fig. 1A). We found that quercetin strongly enhanced the ability of TRAIL to induce cell death in DU-145 cells. Similar trends were observed by Annexin V- and PI-staining (Fig. 1B) and TUNEL assays (Fig. 1C). To evaluate the activation of apoptosis machinery by quercetin and TRAIL, PARP cleavage and caspase activity were determined in the presence of TRAIL, quercetin, or both. As shown in Fig. 1D, PARP (116 kDa) was cleaved in the presence of TRAIL, yielding a characteristic $85-\mathrm{kDa}$ fragment. The combination treatment of TRAIL and quercetin also resulted in elevated caspase- 9 and caspase- 3 activation. In addition, we demonstrated that TRAILinduced sensitization of cells was blocked using Z-VAD-FMK peptide $(20 \mu \mathrm{mol} / \mathrm{l})$, a general caspase inhibitor. These results provide further evidence that TRAIL-induced sensitization of cells to quercetin involves a caspase-dependent pathway.

\section{Quercetin upregulates DR5 expression in prostate cancer cells}

We determined whether quercetin modulation of DR4 and/or DR5 protein levels was involved in its sensitizing effect on TRAIL-induced apoptosis in prostate cancer cells. Fig. 2 shows that quercetinregulated TRAIL-induced apoptosis corresponded with upregulation of DR5. Reverse transcription (RT)-PCR analysis showed that quercetin treatment increased DR5 mRNA levels in a dose- and time-dependent manner (Fig. 2A). In addition, fluorescence-activated cell sorting (FACS) analysis showed that the quercetin increased DR5 protein levels on the surface of DU-145 cells (Fig. 2B). DR5 expression levels in prostate cancer cells increased in a time- and dosedependent manner with quercetin treatment, but DR4 expression levels did not change (Fig. 2C). Quercetin also increased DR5 protein levels dose-dependently in PC3 and LNCaP cells (Fig. 2D), which indicates that upregulation of DR5 may be a common response of various prostate cells to quercetin exposure.

\section{Effect of ectopic expression of DR5 on TRAIL-induced apoptosis}

To characterize the functional significance of DR5 upregulation in TRAIL-induced apoptosis, we employed a myc-DR5 expression vector (Myc-DR5) to induce ectopic expression of DR5 in prostate cancer cells. DU-145 cells transfected with the control plasmid (pcDNA) or Myc-DR5 were treated with TRAIL (5-100 ng/ml) for $4 \mathrm{~h}$ and then subjected to immunoblot analysis. As shown in Fig. 3A, Myc-DR5induced overexpression of DR5 in DU-145 cells enhanced TRAILinduced apoptosis compared with cells transfected with pcDNA. Expression of DR5 and co-activation of PARP were proportional to Myc-DR5 concentration with the treatment of TRAIL $(10 \mathrm{ng} / \mathrm{ml})$ for $4 \mathrm{~h}$ (Fig. 3B). These results suggest that synergistic enhancement of TRAIL-induced apoptosis by quercetin in prostate cancer cells may be due to the upregulation of DR5.
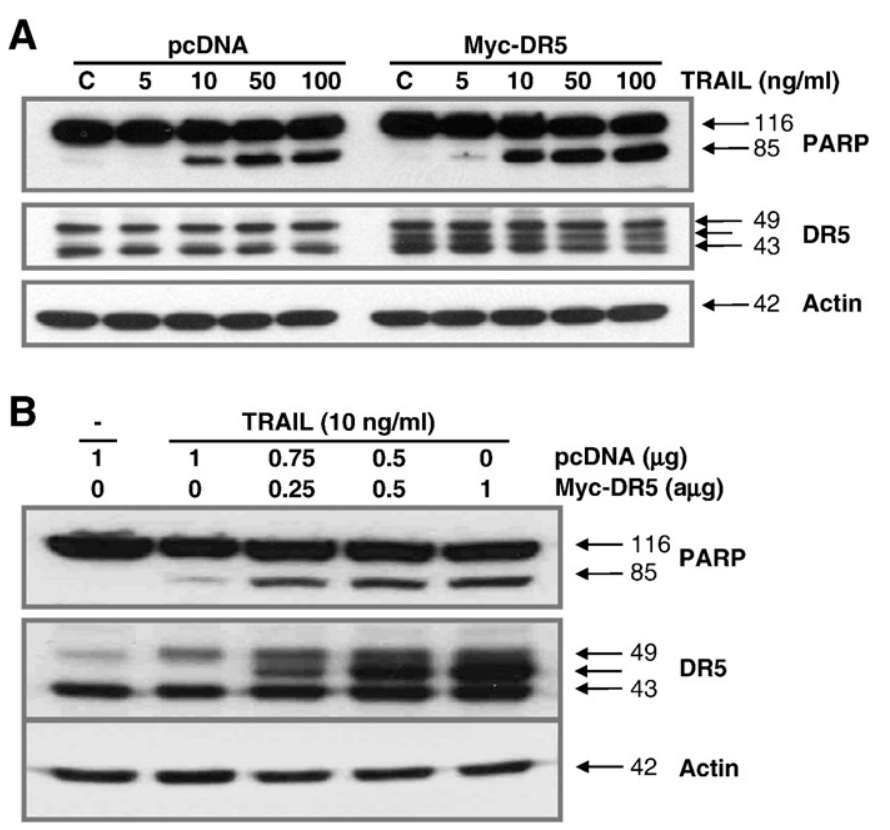

Fig. 3. Effect of the ectopic DR5 expression on TRAIL-induced PARP cleavage. (A) DU-145 cells were transfected with Myc-DR5 plasmid or pcDNA (control). After 4-h treatment with TRAIL for $4 \mathrm{~h}$, Western blot analysis demonstrated that Myc-DR5-induced DR5 overexpression increased apoptosis compared with pcDNA. (B) DU-145 cells were cotransfected with different concentrations of Myc-DR5 plasmid. Western blot analysis demonstrated dose-dependent DR5 expression and PARP activation. Actin was used as an internal standard. 
Quercetin sustains DR5 protein stability

To characterize the mechanism underlying quercetin-induced DR5 upregulation, we examined the effect of quercetin on DR5 transcription, DR5 mRNA stability, and DR5 protein stability. The effect of quercetin on DR5 transcription was determined by DR5 promoter activity after transient transfection of pLUC-DR5, in which the DR5 promoter drives luciferase expression, into DR-145 cells followed by quercetin treatment. As shown in Fig. 4A, quercetin increased DR5 promoter activity, which indicates increased DR5 mRNA synthesis. Next, the effect of quercetin on DR5 mRNA stability was determined by relative decay rates of DR5 mRNA after transcription was inhibited by actinomycin D. DR5 mRNA levels decreased significantly $6 \mathrm{~h}$ after quercetin treatment (Fig. 4B). In order to clarify whether the effect of quercetin on DR5 protein is due to post-translational regulation or not, we performed the experiment to determine the stability of DR5 protein after the treatment of $100 \mathrm{uM}$ quercetin for $16 \mathrm{~h}$. To inhibit de novo protein synthesis after treatment of quercetin, $50 \mathrm{uM}$ of $\mathrm{CHX}$, protein inhibitor, was treated for 0.5 to $4 \mathrm{~h}$ after treatment of quercetin. DR5 protein levels were determined by Western blot analysis and the density was quantified. DR5 protein levels in quercetin-treated cells were maintained at high levels from 0.5 to $4 \mathrm{~h}$ after exposure to CHX, but DR5 protein levels in untreated cells were not detectable $1 \mathrm{~h}$ after exposure to CHX (Fig. 4C). Taken together, these results indicate that quercetin upregulates DR5 expression by increasing transcription and protein stability.

\section{Discussion}

Quercetin, one of the major dietary flavonoids enriched in various fruits and vegetables, has been reported to exert a broad range of pharmacological effects, including antioxidant and anti-inflammatory activities (Lamson and Brignall 2000). Quercetin treatment has been associated with selective antiproliferative effects (Nair et al. 2004) and induction of cell death, predominantly through an apoptotic mechanism, in cancer cell lines but not in normal cells (Chowdhury et al. 2005). Although the underlying mechanisms governing these effects are not yet fully understood, the available evidence collectively indicates that quercetin may be of therapeutic benefit in clinical settings, suggesting its potential use as an anticancer agent or an adjunct to current cancer therapies. We demonstrate here that combined treatment with subtoxic
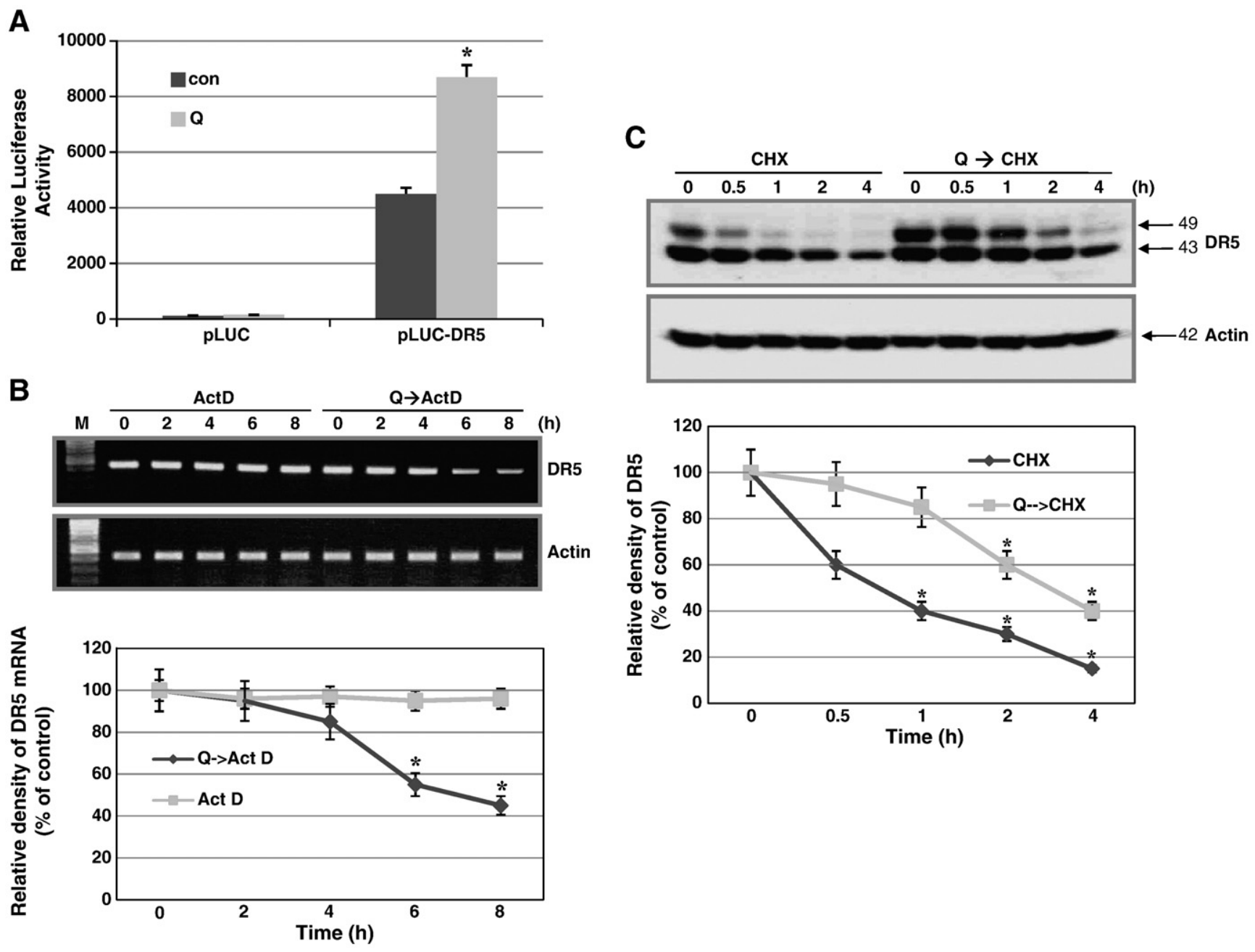

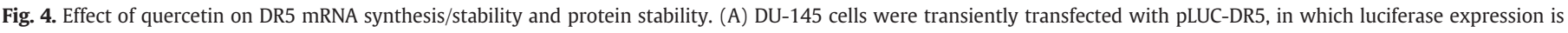

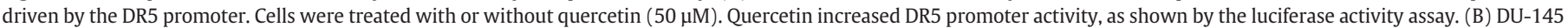

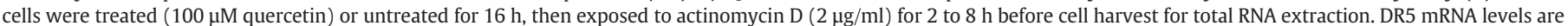

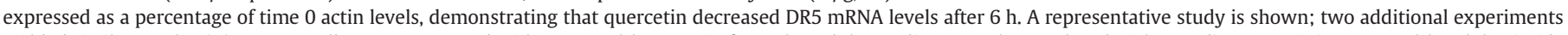

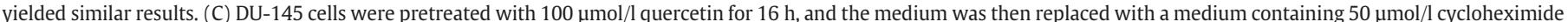

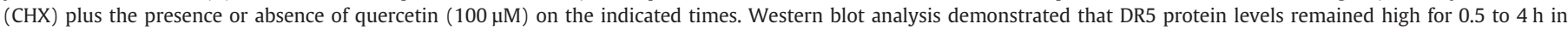

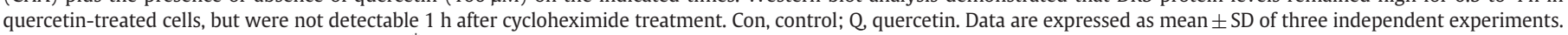
Statistics, Student's $t$-test for unpaired values. ${ }^{*} P<0.05$ versus control. 
doses of quercetin and TRAIL effectively induces apoptotic cell death in TRAIL-resistant prostate cancer cells.

Overexpression of various anti-apoptotic proteins, inhibitors of apoptosis (IAPs), Bcl-2, Bcl-xL, FLICE-like inhibitory proteins (FLIPs), and Akt may confer TRAIL resistance to cancer cells (Chawla-Sarkar et al. 2004; Shankar and Srivastava 2004; Kim et al. 2004; Bai et al. 2005). Kim et al. (2008b) reported that quercetin induced apoptosis in hepatoma cells through activation of TRAIL death pathway in addition to the antiapoptotic protein, FLIP. In those cells, quercetin induced the expression of DR5, but not DR4 by transcriptional levels and translational levels. It has been reported that overexpression of DR5 in TRAIL-resistant cancer cells restored TRAIL sensitivity (Mitsiades et al. 2001). We observed that quercetin-enhanced TRAIL cytotoxicity is mediated through upregulating DR5 expression. Interestingly, quercetin treatment did not affect the levels of other IAP (XIAP, cIAP1, and CIAP2), emphasizing the specific effect of quercetin on DR5 expression. We also showed that quercetin causes a significant increase in the levels of DR5 protein in prostate cancer cells. The increased level of DR5 expression, leading to stimulation of the death receptor pathway, seems to be the cause of the activation of caspase-8 (Fig. 1D). Increased DR5 expression has been highly correlated with sensitivity to TRAIL in some cell lines (Jang et al. 2003). Recent studies have shown that quercetin can augment TRAILinduced apoptosis through upregulating the expression of DR5 in several types of cancer cells (Sonnemann et al. 2005; Singh et al. 2005).

In the search for new therapeutic strategies, we found that quercetin is a potent enhancer of TRAIL-induced apoptosis through induction of DR5 expression specifically in prostate cancer cells (Fig. 2C, D). The critical role of DR5 upregulation by quercetin in TRAIL-mediated apoptosis was confirmed by our finding that ectopic overexpression of DR5 enhanced cell death induced by TRAIL (Fig. 3). DR5 overexpression was due to both increased transcription and increased protein stability by quercetin in human prostate DU-145 cells (Fig. 4A, C). Recently, Kim et al. (2008b) and Chen et al. (2007) reported that treatment with quercetin also sensitizes lung cancer and hepatoma cells to TRAIL-mediated apoptosis via DR5 induction. Recent reports have shown that the stability of DR5 mRNA is tightly regulated by the mRNA-binding protein HuR, which is known to stabilize mRNAs (Kandasamy and Kraft 2008). In the present study, we showed that quercetin stabilized DR5 at the post-translational level (Fig. 4C). Therefore, quercetin may stabilize DR5 protein by inhibiting proteasome-mediated protein turnover.

Here, we provide the first evidence that quercetin is a potent sensitizer for TRAIL-induced apoptosis in human prostate cancer cell lines by upregulating DR5 expression via increased protein stability. Quercetin increased DR5 protein levels dose-dependently in DU-145, PC3, and LNCaP cells, which indicates that upregulation of DR5 may be a common response of prostate cells to quercetin exposure. Enhanced TRAIL-induced apoptosis by quercetin-induced DR5 upregulation is associated with increased activation of the caspase pathway.

\section{Conclusions}

In summary, our results suggest that increased DR5 stability by quercetin may be a novel mechanism underlying the upregulation of DR5 for TRAIL-induced apoptosis in human prostate cancer cells. This work further clarifies the mechanism by which quercetin enhances sensitivity of cancer cells to the apoptotic agent TRAIL.

\section{Conflict of interest statement}

The authors declare no competing financial interests.

\section{Acknowledgments}

This work was supported by the Korea Research Foundation Grant funded by the Korean Government (MOEHRD, Basic Research
Promoting Fund) (KRF-2008-331-C00255), and Kosin University College of Medicine (2007).

\section{References}

Ashkenazi A, Pai RC, Fong S, Leung S, Lawrence DA, Marsters SA, Blackie C, Chang L, McMurtrey AE, Hebert A, DeForge L, Koumenis IL, Lewis D, Harris L, Bussiere J, Koeppen H, Shahrokh Z, Schwall RH. Safety and antitumor activity of recombinant soluble Apo2 ligand. The Journal of Clinical Investigation 104 (2), 155-162, 1999.

Bai J, Sui J, Demirjian A, Vollmer Jr CM, Marasco W, Callery MP. Predominant Bcl-XL knockdown disables antiapoptotic mechanisms: tumor necrosis factor-related apoptosis-inducing ligand-based triple chemotherapy overcomes chemoresistance in pancreatic cancer cells in vitro. Cancer Research 65 (6), 2344-2352, 2005.

Chawla-Sarkar M, Bae SI, Reu FJ, Jacobs BS, Lindner DJ, Borden EC. Downregulation of $\mathrm{Bcl}-2$, FLIP or IAPs (XIAP and survivin) by siRNAs sensitizes resistant melanoma cells to Apo2L/TRAIL-induced apoptosis. Cell Death and Differentiation 11 (8) 915-923, 2004.

Chen W, Wang X, Zhuang J, Zhang L, Lin Y. Induction of death receptor 5 and suppression of survivin contribute to sensitization of TRAIL-induced cytotoxicity by quercetin in non-small cell lung cancer cells. Carcinogenesis 28 (10), 2114-2121, 2007.

Chowdhury SA, Kishino K, Satoh R, Hashimoto K, Kikuchi H, Nishikawa H, Shirataki Y, Sakagami H. Tumor-specificity and apoptosis-inducing activity of stilbenes and flavonoids. Anticancer Research 25 (3B), 2055-2063, 2005.

Ivanov VN, Bhoumik A, Ronai Z. Death receptors and melanoma resistance to apoptosis. Oncogene 22 (20), 3152-3161, 2003.

Jang YJ, Park KS, Chung HY, Kim HI. Analysis of the phenotypes of Jurkat clones with different TRAIL-sensitivities. Cancer Letters 194 (1), 107-117, 2003.

Jung EM, Park JW, Choi KS, Park JW, Lee HI, Lee KS, Kwon TK. Curcumin sensitizes tumor necrosis factor-related apoptosis-inducing ligand (TRAIL)-mediated apoptosis through CHOP-independent DR5 upregulation. Carcinogenesis 27 (10), 2008-2017, 2006.

Kandasamy K, Kraft AS. Proteasome inhibitor PS-341 (VELCADE) induces stabilization of the TRAIL receptor DR5 mRNA through the 3 '-untranslated region. Molecular Cancer Therapeutics 7 (5), 1091-1100, 2008.

Keane MM, Ettenberg SA, Nau MM, Russell EK, Lipkowitz S. Chemotherapy augments TRAIL-induced apoptosis in breast cell lines. Cancer Research 59 (3), 734-741, 1999.

Kim EH, Kim SU, Shin DY, Choi KS. Roscovitine sensitizes glioma cells to TRAILmediated apoptosis by downregulation of survivin and XIAP. Oncogene 23 (2), 446-456, 2004.

Kim EH, Yoon MJ, Kim SU, Kwon TK, Sohn S, Choi KS. Arsenic trioxide sensitizes human glioma cells, but not normal astrocytes, to TRAIL-induced apoptosis via CCAAT/ enhancer-binding protein homologous protein-dependent DR5 up-regulation. Cancer Research 68 (1), 266-275, 2008a.

Kim JY, Kim EH, Park SS, Lim JH, Kwon TK, Choi KS. Quercetin sensitizes human hepatoma cells to TRAIL-induced apoptosis via Sp1-mediated DR5 up-regulation and proteasome-mediated c-FLIPS down-regulation. Journal of Cellular Biochemistry 105 (6), 1386-1398, 2008b.

Kim YH, Jung EM, Lee TJ, Kim SH, Choi YH, Park JW, Park JW, Choi KS, Kwon TK. Rosiglitazone promotes tumor necrosis factor-related apoptosis-inducing ligandinduced apoptosis by reactive oxygen species-mediated up-regulation of death receptor 5 and down-regulation of c-FLIP. Free Radical Biology and Medicine 44 (6), 1055-1068, 2008c.

Kim YH, Lee DH, Jeong JH, Guo ZS, Lee YJ. Quercetin augments TRAIL-induced apoptotic death: involvement of the ERK signal transduction pathway. Biochemical Pharmacology 75 (10), 1946-1958, 2008d.

Kim YH, Lee YJ. TRAIL apoptosis is enhanced by quercetin through Akt dephosphorylation. Journal of Cellular Biochemistry 100 (4), 998-1009, 2007.

Kischkel FC, Lawrence DA, Chuntharapai A, Schow P, Kim KJ, Ashkenazi A. Apo2L/TRAILdependent recruitment of endogenous FADD and caspase- 8 to death receptors 4 and 5. Immunity 12 (6), 611-620, 2000.

Kuo PC, Liu HF, Chao JI. Survivin and p53 modulate quercetin-induced cell growth inhibition and apoptosis in human lung carcinoma cells. The Journal of Biological Chemistry 279 (53), 55875-5585, 2004.

Lamson DW, Brignall MS. Antioxidants and cancer, part 3: quercetin. Alternative Medicine Review 5 (3), 196-208, 2000.

Lawrence D, Shahrokh Z, Marsters S, Achilles K, Shih D, Mounho B, Hillan K, Totpal K, DeForge L, Schow P, Hooley J, Sherwood S, Pai R, Leung S, Khan L, Gliniak B, Bussiere J, Smith CA, Strom SS, Kelley S, Fox JA, Thomas D, Ashkenazi A. Differential hepatocyte toxicity of recombinant Apo2L/TRAIL versions. Nature Medicine 7 (4), 383-385, 2001.

Lee TJ, Kim OH, Kim YH, Lim JH, Kim S, Park JW, Kwon TK. Quercetin arrests G2/M phase and induces caspase-dependent cell death in U937 cells. Cancer Letters 240 (2), 234-242, 2006.

Mitsiades N, Poulaki V, Mitsiades C, Tsokos M. Ewing's sarcoma family tumors are sensitive to tumor necrosis factor-related apoptosis-inducing ligand and express death receptor 4 and death receptor 5. Cancer Research 61 (6), 2704-2712, 2001

Nair HK, Rao KV, Aalinkeel R, Mahajan S, Chawda R, Schwartz SA. Inhibition of prostate cancer cell colony formation by the flavonoid quercetin correlates with modulation of specific regulatory genes. Clinical and Diagnostic Laboratory Immunology 11 (1), 63-69, 2004.

Ozören N, Fisher MJ, Kim K, Liu CX, Genin A, Shifman Y, Dicker DT, Spinner NB, Lisitsyn NA, El-Deiry WS. Homozygous deletion of the death receptor DR4 gene in a 
nasopharyngeal cancer cell line is associated with TRAIL resistance. International Journal of Oncology 16 (5), 917-925, 2000.

Pan G, Ni J, Wei YF, Yu G, Gentz R, Dixit VM. An antagonist decoy receptor and a death domain-containing receptor for TRAIL. Science 277 (5327), 815-818, 1997.

Pitti RM, Marsters SA, Ruppert S, Donahue CJ, Moore A, Ashkenazi A. Induction of apoptosis by Apo-2 ligand, a new member of the tumor necrosis factor cytokine family. The Journal of Biological Chemistry 271 (22), 12687-12690, 1996.

Psahoulia FH, Drosopoulos KG, Doubravska L, Andera L, Pintzas A. Quercetin enhances TRAIL-mediated apoptosis in colon cancer cells by inducing the accumulation of death receptors in lipid rafts. Molecular Cancer Therapeutics 6 (9), 2591-2599, 2007.

Shankar S, Srivastava RK. Enhancement of therapeutic potential of TRAIL by cancer chemotherapy and irradiation: mechanisms and clinical implications. Drug Resistance Updates 7 (2), 139-156, 2004.

Sheridan JP, Marsters SA, Pitti RM, Gurney A, Skubatch M, Baldwin D, Ramakrishnan L Gray CL, Baker K, Wood WI, Goddard AD, Godowski P, Ashkenazi A. Control of TRAIL-induced apoptosis by a family of signaling and decoy receptors. Science 277 (5327), 818-821, 1997.

Singh TR, Shankar S, Srivastava RK. HDAC inhibitors enhance the apoptosis-inducing potential of TRAIL in breast carcinoma. Oncogene 24 (29), 4609-4623, 2005.

Sonnemann J, Gänge J, Kumar KS, Müller C, Bader P, Beck JF. Histone deacetylase inhibitors interact synergistically with tumor necrosis factor-related apoptosis- inducing ligand (TRAIL) to induce apoptosis in carcinoma cell lines. Investigational New Drugs 23 (2), 99-109, 2005.

Sprick MR, Weigand MA, Rieser E, Rauch CT, Juo P, Blenis J, Krammer PH, Walczak H. FADD/MORT1 and caspase- 8 are recruited to TRAIL receptors 1 and 2 and are essential for apoptosis mediated by TRAIL receptor 2 . Immunity 12 (6), 599-609, 2000.

Tanigawa S, Fujii M, Hou DX. Stabilization of p53 is involved in quercetin-induced cell cycle arrest and apoptosis in HepG2 cells. Bioscience, Biotechnology, and Biochemistry 72 (3), 797-804, 2008.

Walczak H, Degli-Esposti MA, Johnson RS, Smolak PJ, Waugh JY, Boiani N, Timour MS, Gerhart MJ, Schooley KA, Smith CA, Goodwin RG, Rauch CT. TRAIL-R2: a novel apoptosis-mediating receptor for TRAIL. The EMBO Journal 16 (17), 5386-5397, 1997.

Walczak H, Miller RE, Ariail K, Gliniak B, Griffith TS, Kubin M, Chin W, Jones J, Woodward A, Le T, Smith C, Smolak P, Goodwin RG, Rauch CT, Schuh JC, Lynch DH. Tumoricidal activity of tumor necrosis factor-related apoptosis-inducing ligand in vivo. Nature Medicine 5 (2), 157-163, 1999.

Wang S, El-Deiry WS. TRAIL and apoptosis induction by TNF-family death receptors. Oncogene 22 (53), 8628-8633, 2003. 